\title{
Erratum to: Genetic structure and diversity of the Banana bunchy top virus population on Sumatra Island, Indonesia
}

\author{
Yuya Chiaki • Nasril Nasir • Henny Herwina $\cdot$ Jumjunidang • \\ Ayaka Sonoda • Tomohiro Fukumoto • Masayuki Nakamura • Hisashi Iwai
}

Published online: 30 May 2015

(C) Koninklijke Nederlandse Planteziektenkundige Vereniging 2015

\section{Erratum to: Eur J Plant Pathol \\ DOI 10.1007/s10658-015-0669-9}

In the base sequence of Type A and B of Fig. 2, "T" which is the 14th from the 5 'end is a mistake, and a right base is " $\mathrm{A}$ ". Please replace with the figure indicated here.

The online version of the original article can be found at http://dx. doi.org/10.1007/s10658-015-0669-9.

Y. Chiaki $\cdot$ A. Sonoda $\cdot$ T. Fukumoto $\cdot$ M. Nakamura $\cdot$

H. Iwai $(\bowtie)$

Faculty of Agriculture, Kagoshima University, 1-21-24,

Korimoto, Kagoshima 890-0065, Japan

e-mail: topcrop@agri.kagoshima-u.ac.jp

Y. Chiaki $\cdot$ T. Fukumoto $\cdot$ M. Nakamura $\cdot$ H. Iwai The United Graduate School of Agricultural Science, Kagoshima University, 1-21-24, Korimoto,

Kagoshima 890-0065, Japan

N. Nasir $\cdot$ H. Herwina

Biology Department, Faculty of Mathematics and Natural Science, Andalas University, Padang 25163 West Sumatra, Indonesia

Jumjunidang

Indonesian Tropical Fruits Research Institute, Solok 52213

West Sumatra, Indonesia

T. Fukumoto

Fruit Tree Branch, Kagoshima Prefecture Institute for Agricultural Development, Tarumizu, Kagoshima 891-2112, Japan 
Fig. 2 The secondary structure of the stem-loop region of DNA-U3 in BBTV Sumatra isolates.

Sequence differences are indicated with boxes

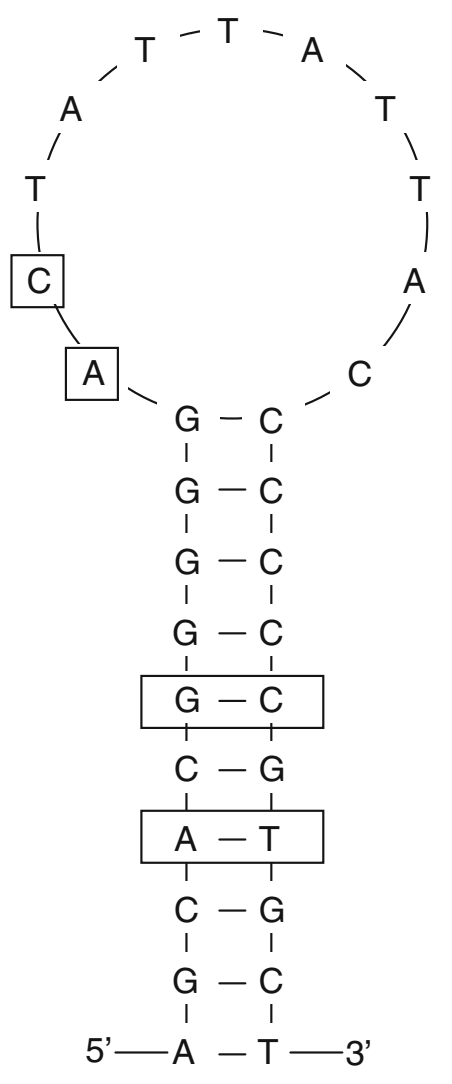

Type A

North Sumatra, West

Sumatra and Riau, Taiwan,

Pakistan, India and China

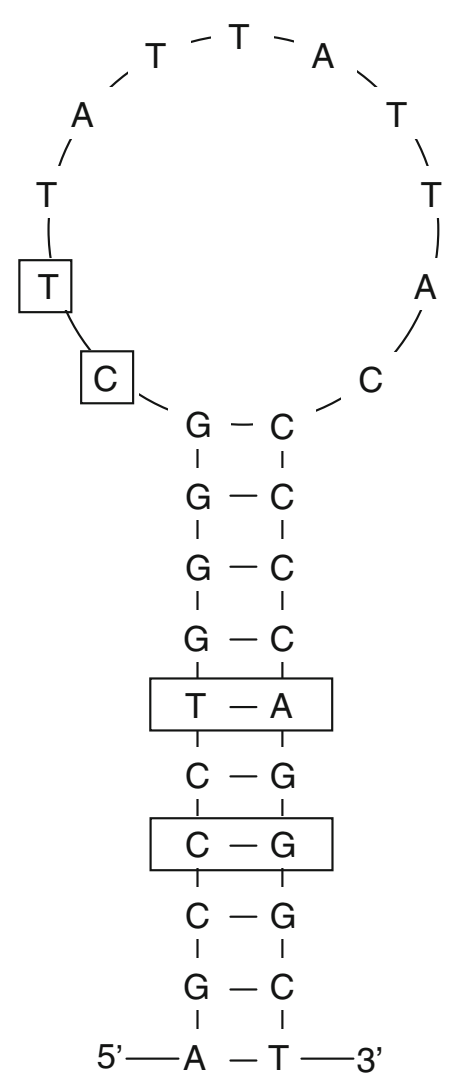

Type B

South region of Sumatra Island, Pakistan, Tonga, China and Rwanda 